\title{
Erratum to: Extracranial contamination in the INVOS 5100C versus the FORE-SIGHT ELITE cerebral oximeter: a prospective observational crossover study in volunteers
}

\author{
Steven Greenberg, MD • Glenn Murphy, MD • Torin Shear, MD • Aashka Patel, BS • \\ Andrew Simpson · Joseph Szokol, MD · Michael J. Avram, PhD · Jeffery Vender, MD
}

Published online: 17 February 2016

(C) Canadian Anesthesiologists' Society 2016

Erratum to: Can J Anesth/J Can Anesth (2016) 63:24-30 DOI 10.1007/s12630-015-0451-7

In the article entitled: "Extracranial contamination in the INVOS 5100C versus the FORE-SIGHT ELITE cerebral oximeter: a prospective observational crossover study in volunteers" published in the January 2016 issue of the Journal, Can J Anesth 2016; 63: 24-30, in the second column of page 29 , the second to last sentence of the first paragraph should read: "Another study by Sorenson et al. examined 15 healthy males under different physiologic conditions". The publisher apologizes most sincerely for this error.

The online version of the original article can be found under doi:10.1007/s12630-015-0451-7.

S. Greenberg, MD $(\varangle) \cdot$ G. Murphy, MD · T. Shear, MD .

A. Patel, BS · A. Simpson - J. Szokol, MD · J. Vender, MD NorthShore University HealthSystem, 2650 Ridge Ave.,

Evanston, IL 60201, USA

e-mail: sbgreenb@gmail.com

S. Greenberg, MD · G. Murphy, MD · T. Shear, MD •

J. Szokol, MD · J. Vender, MD

Pritzker School of Medicine, University of Chicago, Chicago,

IL, USA

M. J. Avram, PhD

Northwestern University Feinberg School of Medicine, Chicago,

IL, USA 